\title{
Genetic Variations and Cultivar Purity within the G. hirsutum Cultivars via RAPD Marker
}

\author{
Farah Raheel', Muhammad Kauser Nawaz Shah'2, Muhammad Shahid Iqbal',3, \\ Ijaz Rasool Noorka ${ }^{4}$, Zareen Sarfraz ${ }^{5}$ \\ ${ }^{1}$ Government Postgraduate College (w), Multan, Pakistan \\ ${ }^{2}$ PMAS Arid Agricultural University, Rawalpindi, Pakistan \\ ${ }^{3}$ Ayub Agriculture Research Institute, Faisalabad, Pakistan \\ ${ }^{4}$ Department of Plant Breeding and Genetics, University College of Agriculture, University of Sargodha, \\ Sargodha, Pakistan \\ ${ }^{5}$ National Institute of Biotechnology and Genetic Engineering, Faisalabad, Pakistan \\ Email: shahidkooria@gmail.com
}

Received 20 January 2015; accepted 10 February 2015; published 15 February 2015

Copyright @ 2015 by authors and Scientific Research Publishing Inc.

This work is licensed under the Creative Commons Attribution International License (CC BY).

http://creativecommons.org/licenses/by/4.0/

(c) (i) Open Access

\section{Abstract}

To assess genetic variation within a cultivar, four commercial varieties with five individual $G$. hirsutum genotypes and their bulk were assayed with selected forty 10-mer RAPDs per cultivar via PCR. CIM-473 cultivar showed amplification of 321 bands in total per primer with an average of 8 bands. A range of similarity i.e.; $80 \%-100 \%$ within the cultivar has been observed for minimum and maximum respectively. CIM-448 showed amplification of 300 bands in total per primer with an average of 7.5 bands. Maximum similarity of $95 \%$ and minimum similarity of $84 \%$ was observed within the cultivar. In CIM-1100 the total numbers of fragments amplified are 304, with the average of 7.6 bands per primer and are $12 \%-20 \%$ polymorphic. Similarly, in NIAB-78 the total numbers of fragments amplified were 310 , with the average of 7.7 bands per primer. The reliability of RAPD technique for finding genetic resemblances is indicated by the mentioned results. Numerous groups within 5 individual genotypes bulk among 4 cultivars of $G$. hirsutum $L$. have been through cluster analysis which was by the unweighted pair group method of arithmetic means (UPGMA). Dendrograms have been used for showing cultivar relationship.

\section{Keywords}

Polymerase Chain Reaction (PCR), G. hirsutum, RAPD, Variation within the Cultivars

How to cite this paper: Raheel, F., Shah, M.K.N., Iqbal, M.S., Noorka, I.R. and Sarfraz, Z. (2015) Genetic Variations and Cultivar Purity within the G. hirsutum Cultivars via RAPD Marker. American Journal of Plant Sciences, 6, 392-404. 


\section{Introduction}

Cotton (G. hirsutum L.) is one of the main cash crops and a major contributor to financial stability and economic viability of Pakistan. A cultivar is a particular variety of a plant species or hybrid i.e. being cultivated and/or is recognized as a cultivar (ICNCP). It is a population of homogenous cultivated plants and has genetic traits in common. Identity and reproducibility are inherent features of cultivars.

Origin of domesticated cotton possesses a number of extremely interesting ecological and genetical problems. Nature of genetic material could be responsible for different reports on the degree of perceived variations in cotton [1] [2]. Linos et al. [3] reported that variations in the DNA sequences are identified by molecular markers which cannot detect the changes in the products of transcribed genes like biochemical and morphological markers. Moreover, several cultivars in a species showed a range of agroclimatic conditions required for the production and growth of cotton. The study provides useful information for the selection of parents in the development of cotton cultivars and hybrids as well.

Morphological features commonly used for identification vary with the species, but may include height, seed colour, flower colour, size and nature of specific floral structures and many others. These characteristics should be genetically stable within the cultivars so they will reappear when the cultivars is grown again [3] [4]. Performance differences among cultivars are usually more difficult to identify than morphological features because they are more likely to be affected by the environment or more complex inheritance. The inherent characteristics influencing performance of the improved cultivars need to be genetically stable and reproducible.

Overall yield potential is the most important characteristics by which cultivar performance is measured. Yield potential is evaluated by growing the cultivars in the field and measuring its production in comparison with yield of standard cultivars under similar environmental conditions [5]. Establishing genetic similarities and studying extent of diversity among various cultivars has become possible by keeping an in-depth characterization of cultivars.

Phenotype is an interaction between genotype and environment. These both factors might be a major source of variability. This result has great differences in variability between strains from different varieties; strains from the same variety should be quite similar, because plants that make up a variety would have nearly similar combinations of genes which act harmoniously with each other and the environment to produce a good phenotype. Genotypes from different varieties would have harmonious but different, combinations of genes; the strains from the same variety would not be expected to differ very much and they would have little more variability than strains derived from doubled haploids. Most variations might be from response of variable weather and independent of the plants inherited properties.

Variations between plants in a row (heterogeneity) might be enormous because ancestral plants with a wide range of properties contributed to the strain, and genetic segregation would produces with different assortments of properties. By using double haploid strains all gametes produced by anyone haploid plant or strain should be genetically identical. Heterozygosity or homozygosity might have important effects on variability. Lerner [6] concluded that a pair of dissimilar genes would be better able to buffer environmental fluctuations during development than would a pair of identical genes, thus producing less variability for heterozygotes. According to Gustafssen [7] a pair of dissimilar genes could respond to all environments, thus producing more variability for heterozygotes. By comparing these two theories, different populations each composed of genetically identical plants, homozygous populations from self doubled haploids, and heterozygous F1 populations from crossing two double haploids were produced.

In Pakistan, the cotton crop faces the dual hazard of biotic and abiotic stresses, which result in lower yields. The principal constituent of plant breeding is to have knowledge regarding genetic relationship and germplasm diversity. Recently, in cereals the importance of wide genetic base for resistance regarding diseases has been promoted [8]. Moreover, in order to upgrade the productivity of crop, future breeding program is dependent on the presence of genetic variability. There is a need to analyze the genetic variability in the presently utilized gene pool of cotton for widening the genetic base required for a prolonged successful cultivar development program. Therefore, development of cultivars with broad genetic base is required for attaining the level of independency and permanency. DNA markers that have been originated from particular parental plant can be identified by fingerprinting the DNA of parents and their progeny. The offspring with desirable parental traits can be identified by plant breeders with the help of these markers for using them in breeding program. For selecting the young seedlings in which the trait is not expressing itself or the plants which are growing in such an environ- 
ment where their genetic factors are not expressing like greenhouses, this practice can work there for the breeders. Such type of benefits shrinks the time required to establish new cotton cultivars. Also in the area of gene cloning, the existence of DNA marker in the vicinity of desired gene has become a valued initial step [9] [10] especially in situationsviz; complex agricultural trait being affected by that particular gene and the protein product is unavailable [11]. Due to the growing of limited number of cultivars, the broad genetic diversity existing in the germplasm is not becoming expressed in the field. If the situation continues with growing of a specific cultivar on huge area of land the genotype will be more vulnerable to the diseases. It has been reported by Bowman et al. [12] that the genetic diversity in the field cannot be guaranteed by the diversity existing in the cultivar. In cotton [1] and rye [13], the polymorphism regarding amplification patterns of individual plants has been shown earlier.

\section{Materials and Methods}

\subsection{Plant Material}

First, confirm that you have the correct template for your paper size. This template has been tailored for output on the custom paper size $(21 \mathrm{~cm} \times 28.5 \mathrm{~cm})$.

Four elite cultivars of different morphology were selected to study the genetic variation within each cultivar. All the plant materials were collected from Central Cotton Research Institute, Multan. Main features of the selected plant materials are presented in Table 1.

\subsection{DNA Extraction and Polymerase Chain Reaction (PCR)}

The extraction of DNA from the cotton sample is a crucial step for PCR based DNA markers. 5 - 6 healthy leaves from different plants per cultivar were collected for DNA extraction as described by [14]. The DNA was further purified by repeated extraction. DNA concentration was run on $1 \%$ agarose gel electrophoresis. The purity and concentration of DNA was measured with spectrophotometer (GENESYS 2). The concentration of the DNA sample was calculated as $(\mu \mathrm{g} / \mathrm{ml})=$ O.D $260 \times 2.5[15]$.

The PCR-RAPD reaction was optimized for the amplification reaction [16]. The amplification programme consisted of initial denaturation for $2 \mathrm{~min}$, followed by 35 cycles with a denaturation step at $94^{\circ} \mathrm{C}$ for 1 minute, with an annealing step of $37^{\circ} \mathrm{C}$ for 1 minute and an extension step at $72^{\circ} \mathrm{C}$ for 2 minutes. Bands were viewed using a UV trans-illuminator [17]. The data was analyzed and resulting matrix was used to calculate the Jaccard's Similarity Coefficient [18]. Un-weighted pair-group arithmetic mean average (UPGMA) analysis was employed for the construction of dendrogram. The statistical analysis was carried out with MVSP, computer package (Version 2.1).

\section{Results}

Before you begin to format your paper, first write and save the content as a separate text file. Keep your text and graphic files separate until after the text has been formatted and styled. Do not use hard tabs, and limit use of hard returns to only one return at the end of a paragraph. Do not add any kind of pagination anywhere in the paper. Do not number text heads - the template will do that for you.

Finally, complete content and organizational editing before formatting. Please take note of the following items when proofreading spelling and grammar:

Stability in cotton production is necessary for the stability of Pakistan which has cotton based economy. On

Table 1. List of cultivars of G. hirsutum to determine the genetic variation within each cultivar.

\begin{tabular}{cccc}
\hline Sr. No. & Variety & Year of release & Origin \\
\hline 1 & CIM-473 & 2002 & CCRI, Multan \\
2 & CIM-448 & 2000 & CCRI, Multan \\
3 & CIM-1100 & 1996 & CCRI, Multan \\
4 & NIAB-78 & 1983 & NIAB, Faisalabad \\
\hline
\end{tabular}


the basis of RAPD tests, 4 commercial varieties (CIM-473, CIM-448, CIM-1100, NIAB-78) were selected, in order to detect the genetic differences and similarities among the cultivars. Genomic DNA of 5 individual plants and bulk of every cultivar was amplified with 40 primers in total per cultivar. Typical RAPD amplification profiles were presented in the relevant place. The description of results of each cultivar is as follows:

\subsection{CIM-473}

The amplification profiles of five single plants and one parent/bulk of CIM-473 shows polymorphism with 40 primers and can be used for study of intra-varietal variations. The maximum similarity (100\%) and minimum similarity (80\%) was observed within the cultivar. There has been obtained 321 bands in total from single primer with an average of 8.0 bands (Figure 1 and Figure 2). A range of 8 - 10 amplified fragments was observed from single RAPD primer. Maximum similarity 100\% was observed between plant 1 and plant 3; plant 4 and bulk of CIM-473 and lowest similarity 80\% was observed between plant 2 and plant 5 (Table 2). Five single plants and the bulk of CIM-473 cultivar clustered into three distinct groups (Figure 3).

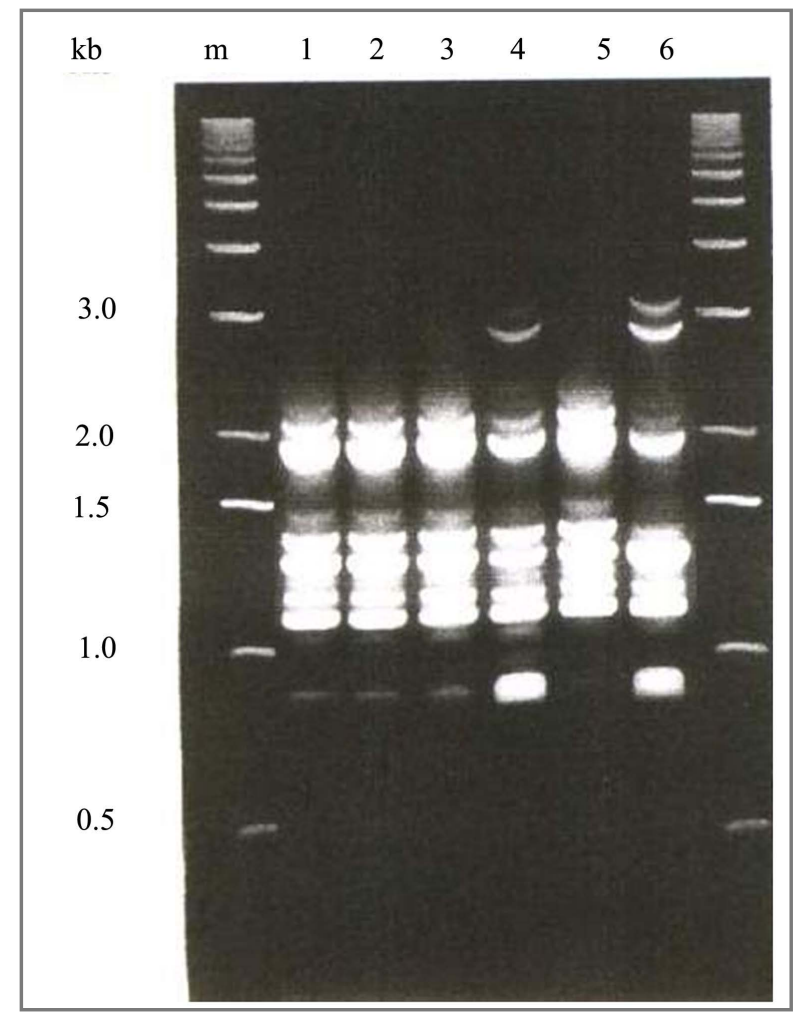

Figure 1. RAPDs generated from five single plants and bulk of CIM-473 by using primer OPY-20.

Table 2. Similarity coefficients within five single plants and bulk of CIM-473. The letters P1 - P5 are representing 1 - 5 single plants and CIM-473 representing bulk of the cultivar.

\begin{tabular}{cccccc}
\hline & P1 & P2 & P3 & P4 & \\
P1 & 1 & & & & \\
P2 & 0.91 & 1 & & & \\
P3 & 1.0 & 0.92 & 1 & 1 & 1 \\
P4 & 0.90 & 0.81 & 0.93 & 0.81 & 0.80 \\
P5 & 0.93 & 0.80 & 0.91 & 1.0 & 1 \\
CIM-473 & 0.92 & 0.82 & 0.94 & & \\
\hline
\end{tabular}




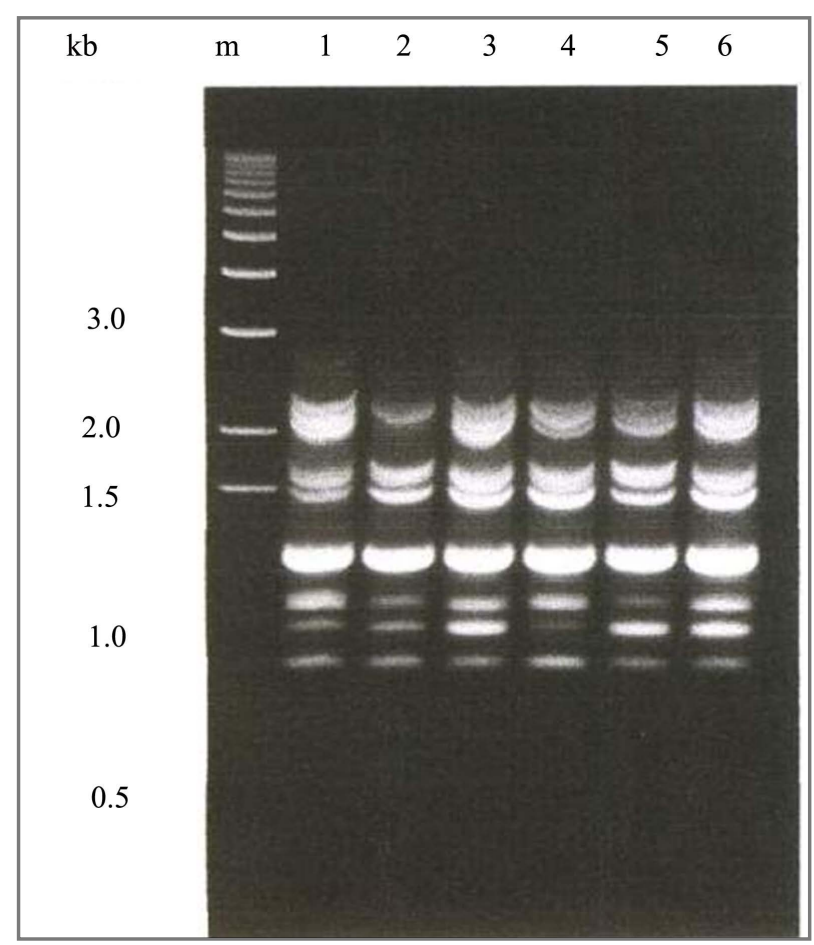

Figure 2. RAPDs generated from five single plants and bulk of CIM-473 by using primer OPZ-20.

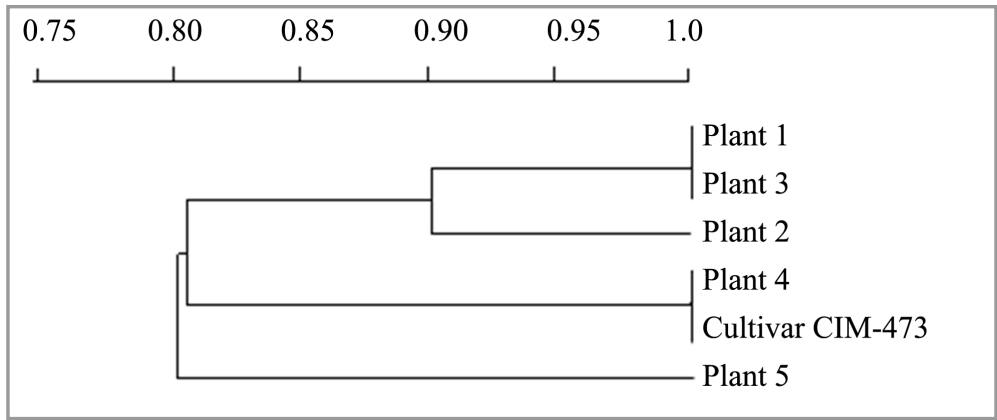

Figure 3. Dendrogram of five single plants and bulk of CIM-473 based on 321 RAPD bands from 40 different primers.

\subsection{CIM-448}

Five single plants and bulk/parent plant of CIM-448 were amplified by using 10-mer primers. The maximum similarity (95\%) and minimum similarity (84\%) was observed within the cultivar. There has been observed amplification of 300 bands in total per primer with an average of 7.5 bands. The coefficients of similarity were ranging from 0.84 to 0.95 (Table 3). A maximum similarity of $95 \%$ has been observed between plant 2 and bulk of CIM-448, plant 4 and bulk of CIM-448; and lowest similarity 84\% was observed between plant 1 and plant 2 . Five single plants and the bulk of CIM-448 cultivar clustered into two distinct groups (Figure 6).

\subsection{CIM-1100}

The DNA of five single plants and the bulk of CIM-1100 were examined to generate RAPD-PCR bands by using 40, 10-mer primers in order to identify variation within the plants and cultivar CIM-1100. Majority of the primers showed amplification in a range of 7 - 10 fragments. Typical RAPD amplification profiles are illustrated in Figure 7 \& Figure 8. The banding pattern produced with two primers (OPA-05, OPI-15) showed monomorphic 


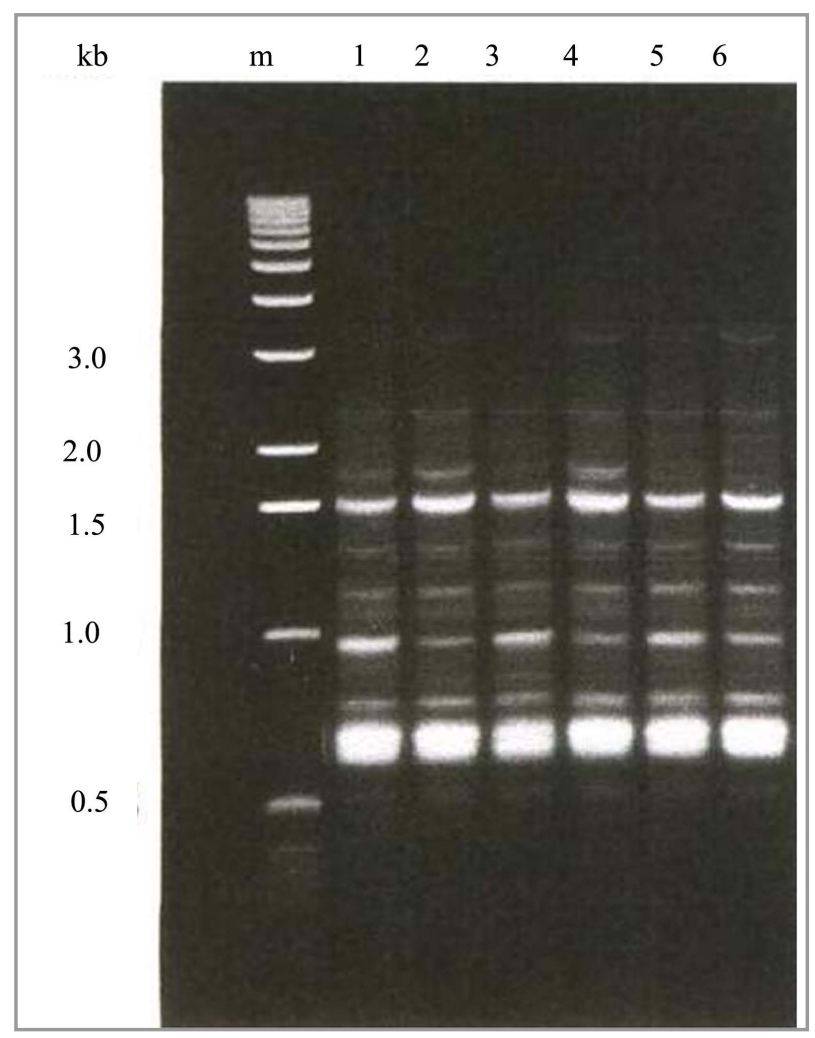

Figure 4. RAPDs generated from five single plants and bulk of CIM-448 by using primer OPJ-03.

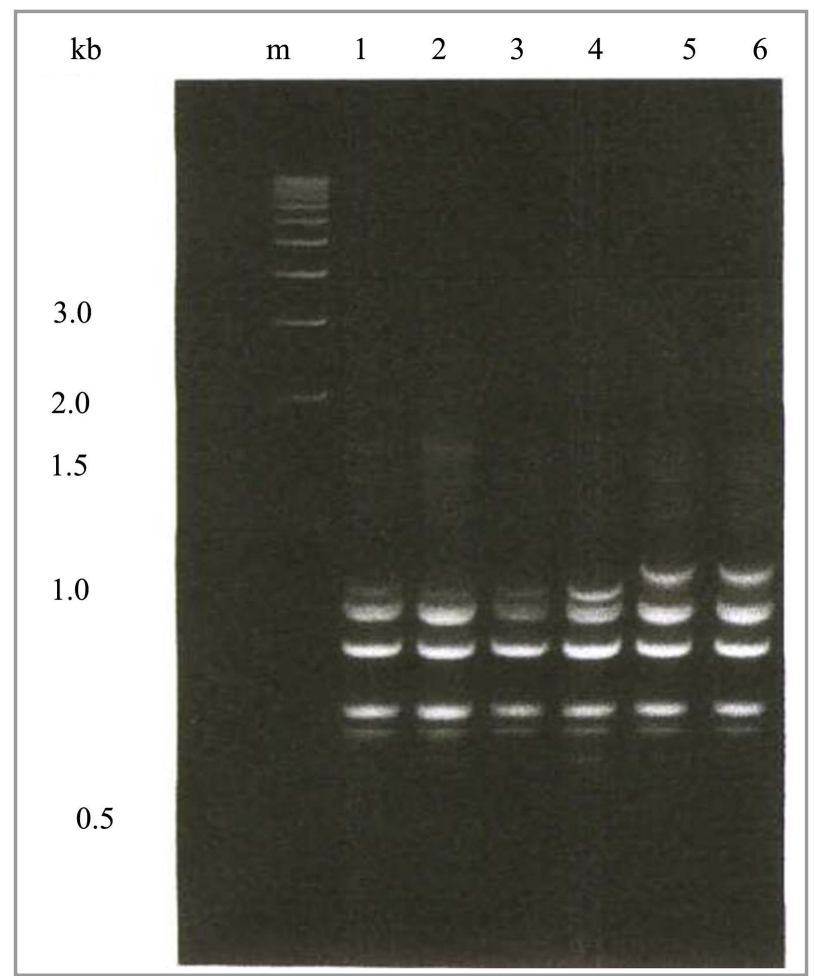

Figure 5. RAPDs generated from five single plants and bulk of CIM-448 by using primer OPN-12. 


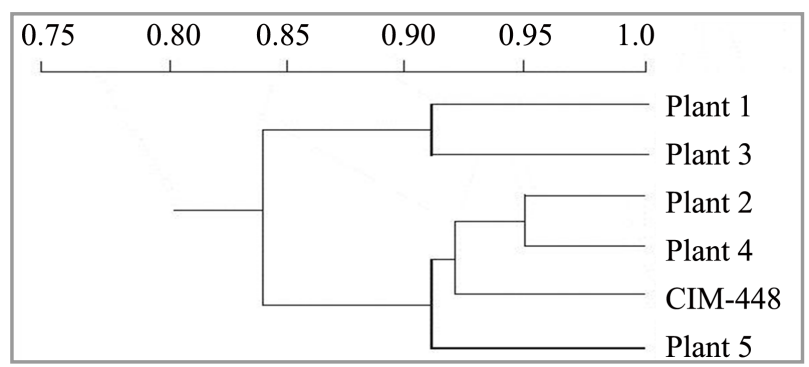

Figure 6. Dendrogram of five single plants and bulk of CIM448 based on 300 RAPD bands from 40 different primers.

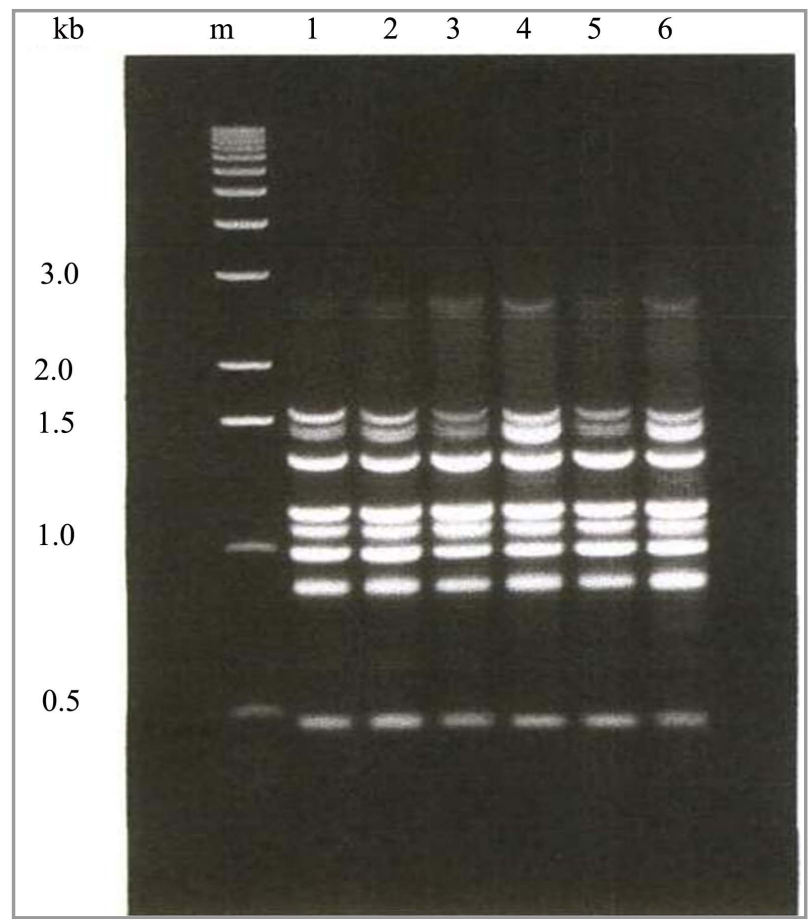

Figure 7. RAPDs generated from five single plants and bulk of CIM-1100 by using primer OPA- 05 .

Table 3. Similiraty coefficients within five single plants and bulk of CIM-448. The letters P1 - P5 are representing 1 - 5 single plants and CIM-473 reprenting bulk of the cultivar.

\begin{tabular}{ccccccc}
\hline & P1 & P2 & P3 & P4 & P5 & CIM-448 \\
\hline P1 & 1 & & & & \\
P2 & 0.84 & 1 & & & & 1 \\
P3 & 0.91 & 0.85 & 1 & 1 & 0.87 & 1 \\
P4 & 0.88 & 0.94 & 0.87 & 0.85 & 0.91 & 0.88 \\
P5 & 0.85 & 0.90 & 0.89 & 0.95 & & \\
CIM-448 & 0.89 & 0.95 & & & & \\
\hline
\end{tabular}

and polymorphic bands. Very little polymorphism was observed with primer OPA-05 (Figure 7). The total number of fragments amplified are 304, with the average of 7.6 bands per primer and are $12 \%$ - 20\% polymor- 
phic. The coefficients of similarity were ranging from 0.80 to 0.92 (Table 4). A maximum similarity of $92 \%$ has been observed between plant 1 and parent/bulk plant of CIM-1100; plant 4 and parent/bulk plant of CIM-1100 and lowest similarity $80 \%$ was observed between plant 1 and plant 5; plant 4 and plant 5 respectively which is $12 \%$ less than the bulk of the cultivar CIM-1100. Five single plants and the bulk of CIM-1100 cultivar clustered into two distinct groups in which plant 1 and bulk of CIM-1100 separated in group 1 with 92\% similarity, while the other plants, plant 2, plant 3, plant 4 and plant 5 stands separately in the dendrogram with an intermediate (81\% - 84\%) similarity. The position of plant 1 in the dendrogram is closer to the bulk of the cultivar CIM-1100 (Figure 9). The reliability of RAPD technique for finding genetic resemblances is indicated very well by the mentioned results.

\subsection{NIAB-78}

Five single plants and the bulk of NIAB-78 were examined to generate RAPD-PCR bands by using 40, 10-mer primers. The total number of fragments amplified was 310, with the average of 7.7 bands per primer. The similarity coefficients ranged from $92 \%$ to $100 \%$ (Table 5). The genetic similarity of five single plants and bulk of NIAB-78 was very high ranging from 0.92 to 1.0 depicting narrow diversity. Maximum similarity $100 \%$ was observed between plant 1 and plant 4; plant 2 and plant 3; plant 2 and bulk of NIAB-78; plant 3 and bulk of

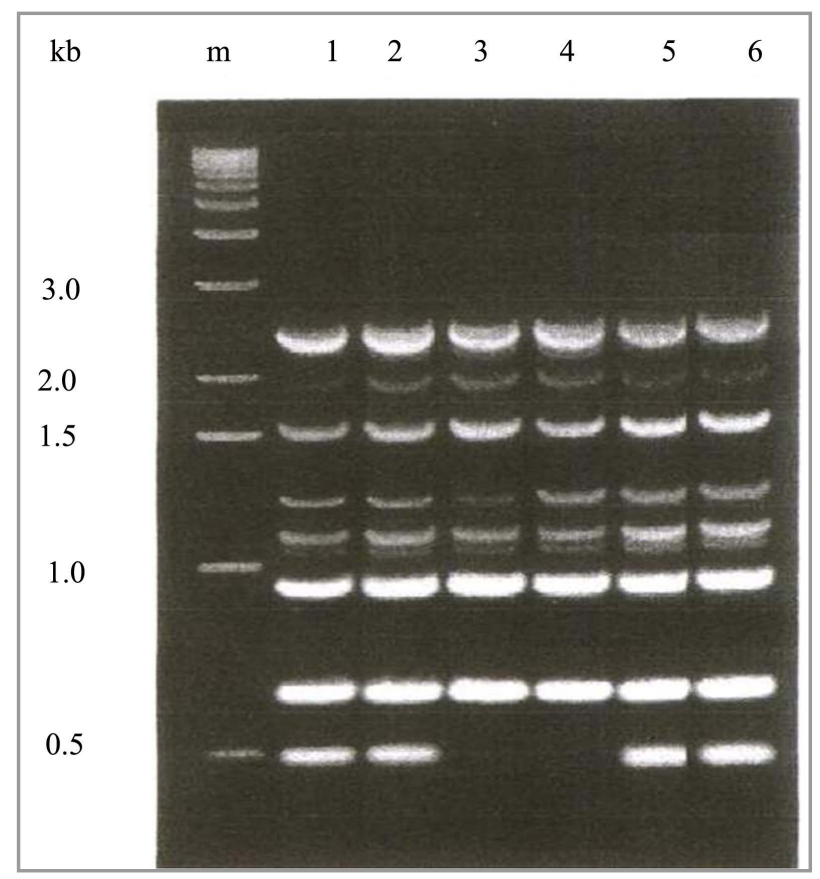

Figure 8. RAPDs generated from five single plants and bulk of CIM-1100 by using primer OPI-15.

Table 4. Similarity coefficients within five single plants and bulk of CIM-1100. The letters P1 - P5 are representing 1 - 5 single plants and CIM-473 representing bulk of the cultivar.

\begin{tabular}{ccccccc}
\hline & P1 & P2 & P3 & P4 & P5 & CIM-1100 \\
\hline P1 & 1 & & & & \\
P2 & 0.83 & 1 & 1 & & \\
P3 & 0.81 & 0.82 & 0.84 & 1 & 1 & 1 \\
P4 & 0.84 & 0.85 & 0.82 & 0.80 & 0.88 & 1 \\
P5 & 0.80 & 0.81 & 0.90 & 0.92 & & \\
CIM-1100 & 0.92 & 0.91 & & & & \\
\hline
\end{tabular}


NIAB-78 respectively. The lowest similarity 92\% was observed between plant 1 and plant 2; plant 4 and plant 5 . Typical RAPD amplification profiles are illustrated in Figure 10 \& Figure 11. The banding pattern produced

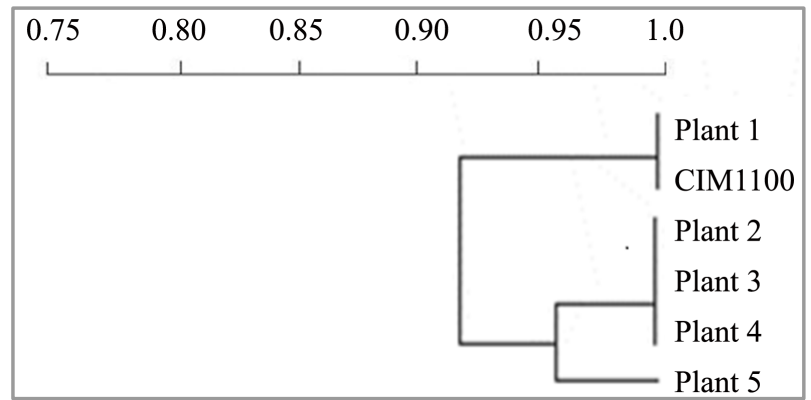

Figure 9. Dendrogram of five single plants and bulk of CIM1100 based on 304 RAPD bands from 40 different primers.

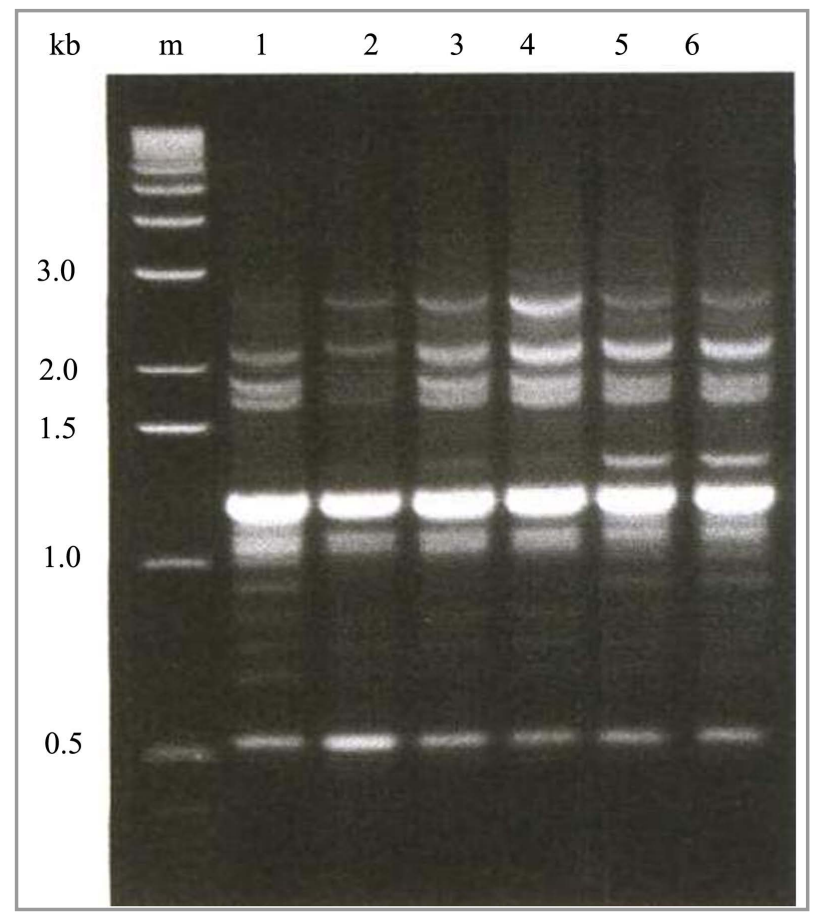

Figure 10. RAPDs generated from five single plants and bulk of NIAB-78 by using primer OPA-15.

Table 5. Similarity coefficients within five single plants and bulk of CIM-78. The letters P1 - P5 are representing 1 - 5 single plants and CIM-473 representing bulk of the cultivar.

\begin{tabular}{ccccccc}
\hline & P1 & P2 & P3 & P4 & P5 & NIAB-78 \\
\hline P1 & 1 & & & & & \\
P2 & 0.92 & 1 & & & & \\
P3 & 0.93 & 1.0 & 1 & & & \\
P4 & 1.0 & 0.93 & 0.94 & 1 & 1 & 1 \\
P5 & 0.97 & 0.96 & 0.95 & 0.92 & 0.97 & \\
NIAB-78 & 0.94 & 1.0 & 1.0 & 0.95 & & \\
\hline
\end{tabular}


with two primers (OPA-15, OPN-06) showed monomorphic and polymorphic bands respectively. Five single plants and the bulk of NIAB-78 cultivar clustered into two distinct groups (Figure 12). For the estimation of genetic resemblances, the mentioned results are good indicators of the reliability of RAPD technique.

\section{Discussion}

The cotton cultivars lose their identical characteristic with the passage of time; this may be due to adulteration of other genotypes from the same species in the cultivar. These studies will help to determine the rate of cultivar deterioration. For the determination of genetic diversity among cultivars of several plant species, broad use of RAPD marker technique has been conducted [19] [20]. In the present study, RAPDs were utilized for the identification of intra-specific polymorphism within the cultivars (CIM-473, CIM-448, CIM-1100, NIAB-78) of G. hirsutum. For the exclusive identification of all cultivars studied, 40 primers per cultivar for the amplification of genomic DNA extracted from five single plants and the bulk of each cultivar, has been utilized. It has become well recognized that the knowledge of genetic associations among accessions within and between species is mandatory for the improvement of plants [21]. Absence of genetic diversity is mainly occurring due to practice involving repeated use of same parents in the breeding program [22]. It has been declared from many of the

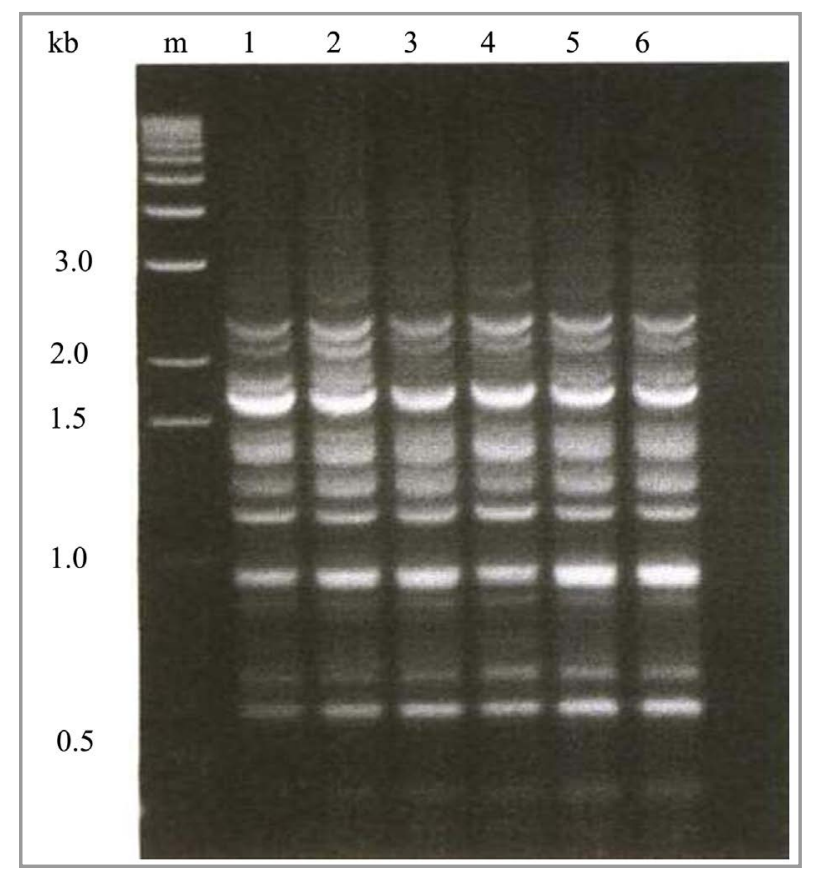

Figure 11. RAPDs generated from five single plants and bulk of NIAB-78 by using primer OPN-06.

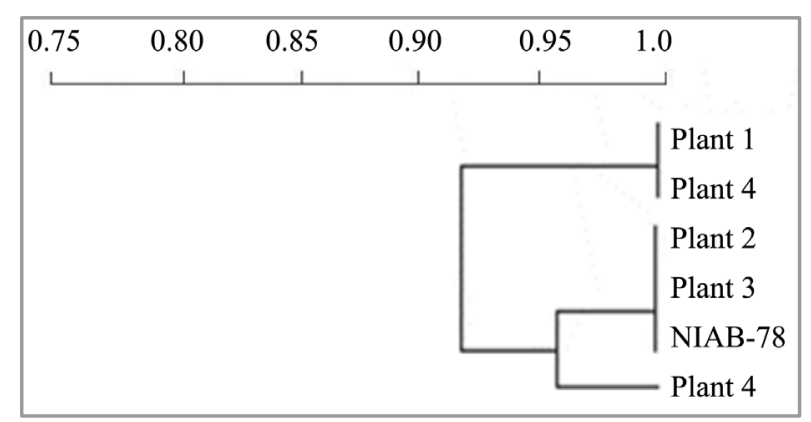

Figure 12. Dendrogram of five single plants and bulk of NIAB-78 based on 310 RAPD bands from 40 different primers. 
studies that poor genetic diversity is prevailing in the germplasm of cultivated American cotton [1] [2]. Genetic similarity can arise from common parentage (pedigree) or from geographical relatedness. Cultivars from similar geographical areas need not always express genetic similarity because germplasm exchange is continuously taking place.

For the determination of homology, the analysis of DNA sequence (RAPD) has become the renowned sensitive method [23]. The commercial cultivars have different age in the field. The long life of any commercial cultivar depends upon the minimum or no variation within the cultivar. This will effect on maximum stability and have a minimum rate of deterioration of the cultivar. The cultivar which deteriorates early indicates that the cultivar had more variation in it and this variation was the main reason of its disappearance from the field. For the determination of genetic relationship in cotton, RAPD markers have been used [1] [6] [24] [25]. The low values of genetic distance observed in the cultivars of G. hirsutum may reflect narrow intra-specific variation. However, in the present study, the range of similarity among the five single plants and bulk of the commercial cultivar NIAB-78 is 92\% - 100\%. Plant 2 and plant 3 showed 100\% similarity to the bulk of NIAB-78 (Table 5). The $100 \%$ similarity of some plants with the bulk of this commercial cultivar indicates that NIAB-78 cultivar is a homogenous plant material. NIAB-78 was released in (1983) and it still covers a large area of Sindh province. It proves that NIAB-78 was the most stable commercial cultivar because it had minimum variation within it. The minimum variation within the NIAB-78 was the main factor that this cultivar exists in the field since last 25 years. Hence, it is quite possible that there is some genetic variation within the cultivar. For determining the genetic diversity within the cultivar NIAB-78, generated RAPD markers were utilized that are presented in Table 5. Reproducibility of RAPDs amplification showed that some markers show more consistent banding patterns within the cultivar. Only 8\% polymorphism was observed in NIAB-78, showing greater genetic uniformity of the cultivar. It has also been reported that genetic uniformity of American cotton was lesser 25 years ago than it is today [26]. Tokatlidis et al. [27] studied and reported the variations within the cotton cultivars for different traits i.e. seed cotton yield, fibre characteristics etc. Similarly genetic variations were observed within cultivars in the present study which are ultimately responsible for the morphological variations. For determining the genetic diversity among 5 individual plants and bulk of commercial cultivar CIM-1100, generated RAPD markers were utilized that is presented in Table 4. Polymorphic profiles were observed within the cultivar (Figure 7 \& Figure 8). The range of similarity among the five single plants and bulk of the commercial cultivar CIM-1100 is $80 \%$ - 92\%. The cultivar CIM-1100 indicates the maximum similarity (92\%) of some plants with the bulk of this commercial cultivar. It was released in (1996) and is now disappeared from the cotton growing regions. One of the reasons for the removal of this cultivar from the field is high level of variations present in the CIM-1100. The estimate of CIM-448 based on the molecular data did not significantly changed from the CIM-1100. Coefficient of similarity was ranging from 0.84 to 0.95 (Table 3). A maximum similarity of $95 \%$ for some plants with the bulk of this commercial cultivar indicates that CIM-448 is also homogenous plant material and the stable commercial cultivar. It was released in (2000) and is now grown in only few cotton growing areas. Williams and Clair [15] also reported that RAPD markers can be of great value in the measurement of intra-specific variation as revealed in Lycopersicon esculentum. In the present study, the commercial cultivar CIM-473 showed similarity coefficients ranged from 0.80 to 1.0 (Table 2). The $100 \%$ similarity of some plants with the bulk of this commercial cultivar indicates that CIM-473 cultivar have maximum homozygosity in it. It was released in (2002) and it covers a large area of Punjab province. The core area of cotton growing is Multan, Bahawalpur and D.G. Khan in Punjab. It proves that CIM-473 was the most stable commercial cultivar because it had minimum variation within it. The minimum variation within the CIM-473 was the main reason that this cultivar was present in the fields of Punjab for several years. Similarly, RAPD markers can be of great value in the measurement of intra-specific variation as revealed in Brassica juncea [28]. The present study has also demonstrated that the RAPD technique can be applied to discriminate variations within cotton cultivars. However different cultivars derived from different parents (CIM-473, CIM-448, CIM-1100, NIAB-78) showed different RAPD patterns. These facts indicate that genetic variation within the cultivated cotton is present, and it will be necessary to make them homogenous to avoid their deterioration. Intra-varietal studies of CIM-473, CIM-448, CIM-1100, NIAB-78 indicates the effectiveness of RAPD technique for the estimation of the genetic similarities among the plants of cotton cultivars. Similar findings were observed by Tafvizi et al. [29] when they studied three cotton cultivars for intra cultivar variations. RAPDs were utilized for the determination of genetic diversity and their results are sporting the findings of the present study. 


\section{References}

[1] Iqbal, M.J., Aziz, N., Saeed, N.A., Zafar, Y. and Malik, K.A. (1997) Genetic Diversity of Some Elite Cotton Varieties by RAPD Analysis. Theoretical and Applied Genetics, 94, 139-144.

[2] Tatineni, V., Cantrell, R.G. and Davis, D.D. (1996) Genetic Diversity in Elite Cotton Germplasm Determined by Morphological Characteristics and RAPDs. Crop Sciecne, 36, 186-192.

[3] Linos, A.A., Bebeli, P.J. and Kaltsikes, P.J. (2002) Cultivar Identification in Upland Cotton Using RAPD Markers. Australian Journal of Agriculture Research, 53, 637-642. http://dx.doi.org/10.1071/AR01129

[4] Raheel, F., Saima, S., Dasti, A.A. and Mahmood, Z. (2005) Morpho-Taxonomic Study of Some Old World Cotton Species. Pakistan Journal of Plant Science, 11, 45-50.

[5] Sudhanshu, J. (1997) Studies on Combining Ability in Intra and Interspecific Crosses of Cotton. Crop Research Hisar, 14, 91-95.

[6] Lerner, I.M. (1954) Genetic Homeostasis. John Wiley and Sons, New York.

[7] Gustafsson, A. (1948) The Effect of Heterozygosity on Variability and Vigour. Hereditos, 32, 263-286. http://dx.doi.org/10.1111/j.1601-5223.1946.tb02779.X

[8] Zhu, Y., Chen, H., Fan, J., Wang, Y., Li, Y., Chen, J., Fan, J., Yang, S., Hu, L., Leung, H., Mew, T.W., Teng, P.S., Wang, Z. and Mundt, C.C. (2000) Genetic Diversity and Disease Control in Rice. Nature, 406, 718-722. http://dx.doi.org/10.1038/35021046

[9] Rommens, J.M., Iannuzzi, M.C., Kerem, B., Drumm, M.L., Melmer, G., Dean, M., Rozmahel, R., Cole, J., Kennedy, D., Hidaka, N., Zsiga, M., Buchwald, M., Riordan, J.R., Tsui, L.C. and Collins, F.S. (1989) Identification of the Cystic Fibrosis Gene: Chromosome Walkihg and Jumping. Science, 245, 1059-1065. http://dx.doi.org/10.1126/science.2772657

[10] Wallace, M.R., Marchuk, D.A., Anderson, R., Letcher, R., Odeh, H.M., Saulino, A.M., Fountain, J.W., Bereton, A., Nicholson, J., Mitchell, A.L., Brownstein, B.H. and Collins, F.S. (1990) Type 1 Neurofibromatosis Gene: Identification of a Large Transcript Disrupted in Three NF1 Patients. Science, 249, 181-186.

[11] Paterson, A.H., De Verna, J.W., Lanini, B. and Tanksley, S.D. (1990) Fine Mapping of Quantitative Trait Loci Using Selected Overlapping Recombinant Chromosomes, in an Interspecies Cross of Tomato. Genetics, 124, 735-742.

[12] Bowman, D.T., May, O.L. and Calhoun, D.S. (1996) Genetic Base of Upland Cotton Cultivars Released between 1970 and 1990. Crop Science, 36, 577-581. http://dx.doi.org/10.2135/cropsci1996.0011183X003600030008x

[13] Iqbal, M.J. and Rayburn, A.L. (1994) Stability of RAPD Markers for Determining Cultivar-Specific DNA Profiles in Rye (Seeale cereal L.). Euphytica, 75, 215-220. http://dx.doi.org/10.1007/BF00025606

[14] Doyle, J.J. and Doyle, J.H. (1990) Isolation of Plant DNA from Fresh Tissue. Focus, 12, 13-15.

[15] Sambrook, J., Fritsch, E.F. and Maniatis, T. (1989) Molecular Cloning: A Laboratory Manual. 2nd Edition, Cold Spring Harbor Laboratory, Cold Spring Harbor.

[16] Williams, C.E. and St. Clair, D.A. (1993) Phenetic Relationships and Levels of Variability Detected by Restriction Fragment Length Polymorphism and Random Amplified DNA Analysis of Cultivated and Wild Accessions of Lycopersicon esculentum. Genome, 36, 619-630. http://dx.doi.org/10.1139/g93-083

[17] Maniatis, T., Fritsch, E.F. and Sambrook, J. (1982) Molecular Cloning: A Laboratory Manual. Cold Spring Harbor Laboratory, Cold Spring Harbor.

[18] Sokal, R.R. and Sneath, P.H.A. (1963) Principles of Numerical Taxonomy. W.H. Freeman, San Francisco.

[19] Rani, V., Parida, A. and Raina, S.N. (1995) Random Amplified Polymorphic DNA (RAPD) Markers for Genetic Analysis in Micropropagated Plants of Populus deltoides Marsh. Plant Cell Reports, 14, 459-462. http://dx.doi.org/10.1007/BF00234055

[20] Soniya, E.V., Banerjee, N.S. and Das, M.R. (2001) Genetic Analysis of Somaclonal Variation among Callus-Derived Plants of Tomato. Current Science, 80, 1213-1215.

[21] Thormann, C.E., Ferreira, M.E., Camargo, L.E.A., Tivang, J.G. and Osborn, T.C. (1994) Comparison of RFLP and RAPD Markers to Estimating Genetic Relationship within and among Cruciferous Species. Theoretical and Applied Genetics, 88, 973-980. http://dx.doi.org/10.1007/BF00220804

[22] Fouilloux, G. and Bannerot, H. (1988) Selection Methods in Common Bean (Phaseolus vulgaris L.). In: Gepts, P., Ed., Genetic Resources of Phaseolus Beans, Klüwer Academic Publishers, Dordrecht, 503-541. http://dx.doi.org/10.1007/978-94-009-2786-5_21

[23] Franca, L.T., Carrilho, E. and Kist, T.B. (2002) A Review of DNA Sequencing Techniques. Quarterly Reviews of Biophysics, 35, 169-200. http://dx.doi.org/10.1017/S0033583502003797 
[24] Multani, D.S. and Lyon, B.R. (1995) Genetic Fingerprinting of Australian Cotton Cultivars with RAPD Markers. Genome, 38, 1005-1008. http://dx.doi.org/10.1139/g95-132

[25] Nie, Y.C., Zuo, K.J., Zhang, X.L., Feng, C.D. and Liu, J.L. (2000) Application of RAPD Markers in Differentiating Germplasm Lines from 4x Gossypium arboreum x G. anomalum x G. hirsutum. Scientia Agricultura Sinica, 33, 2529.

[26] Vas-Esbroeck, G.A. and Bowman, D.T. (1998) Cotton Germplasm Diversity and Its Importance to Cultivar Development. Journal of Cotton Sciences, 2, 121-129.

[27] Tokatlidis, I.S., Tsikrikoni, C., Tsialtas, J.T., Lithourgidis, A.S. and Bebeli, P.J. (2008) Variability within Cotton Cultivars for Yield, Fiber Quality and Physiological Traits. The Journal of Agricultural Science, 146, 483-490. http://dx.doi.org/10.1017/S0021859608007867

[28] Jain, A., Bhatta, S., Banga, S.S., Prakash, S. and Lakshmikumaran, M. (1994) Potential Use of Random Amplified Polymorphic DNA (RAPD) Technique to 201 Study the Genetic Diversity in Indian Mustard (Brassica juncea) and Its Relationship to Heterosis. Theoretical and Applied Genetics, 88, 116-122. http://dx.doi.org/10.1007/BF00222403

[29] Tafvizi, F., Sheidai, M., Farahanei, F., Nourmohammadi, Z. and Alishah, O. (2010) Somaclonal Variation in Three Tetraploid Cotton (Gossypium hirsutum L.) Cultivars. Cotton Research Center, Gorgan. 
Scientific Research Publishing (SCIRP) is one of the largest Open Access journal publishers. It is currently publishing more than 200 open access, online, peer-reviewed journals covering a wide range of academic disciplines. SCIRP serves the worldwide academic communities and contributes to the progress and application of science with its publication.

Other selected journals from SCIRP are listed as below. Submit your manuscript to us via either submit@scirp.org or Online Submission Portal.
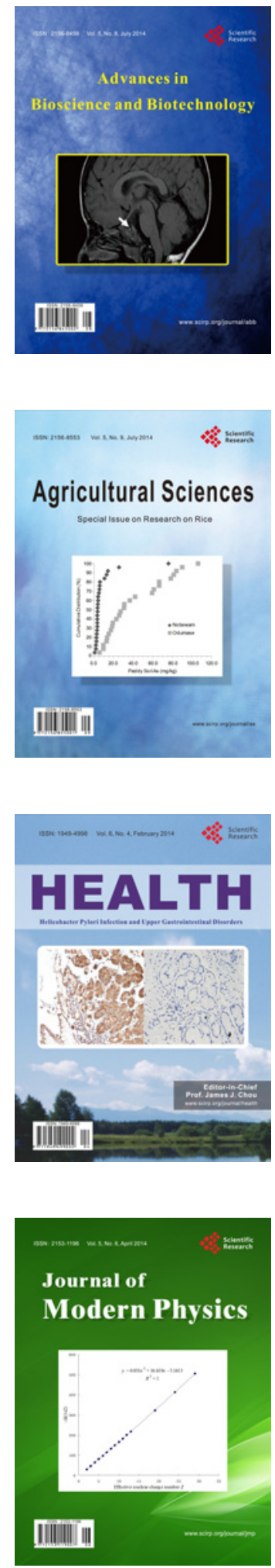
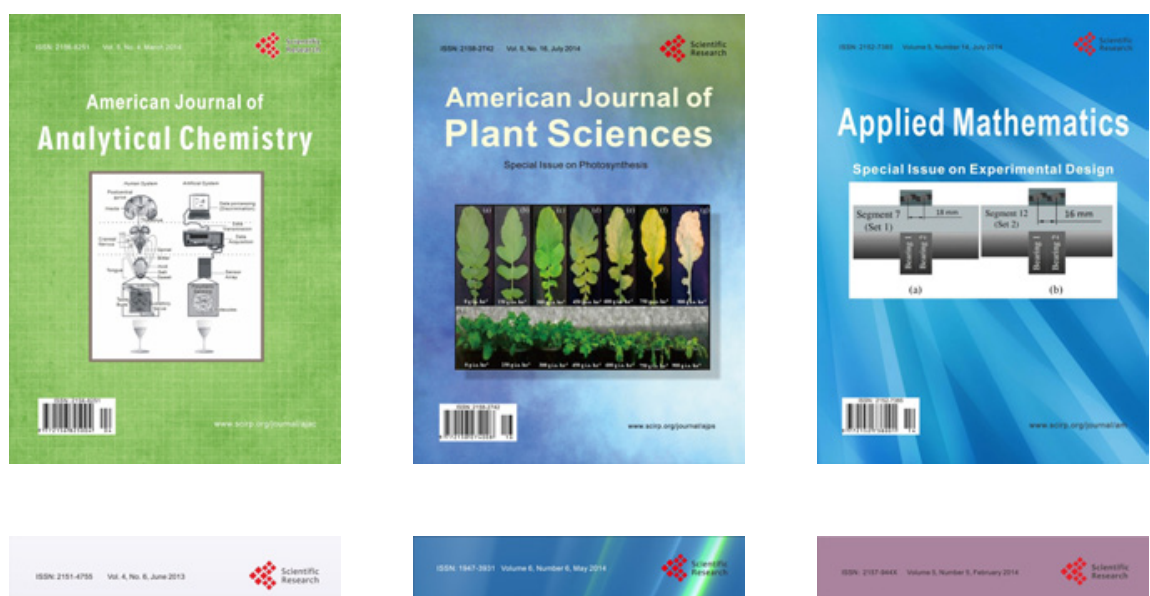

Creative Education
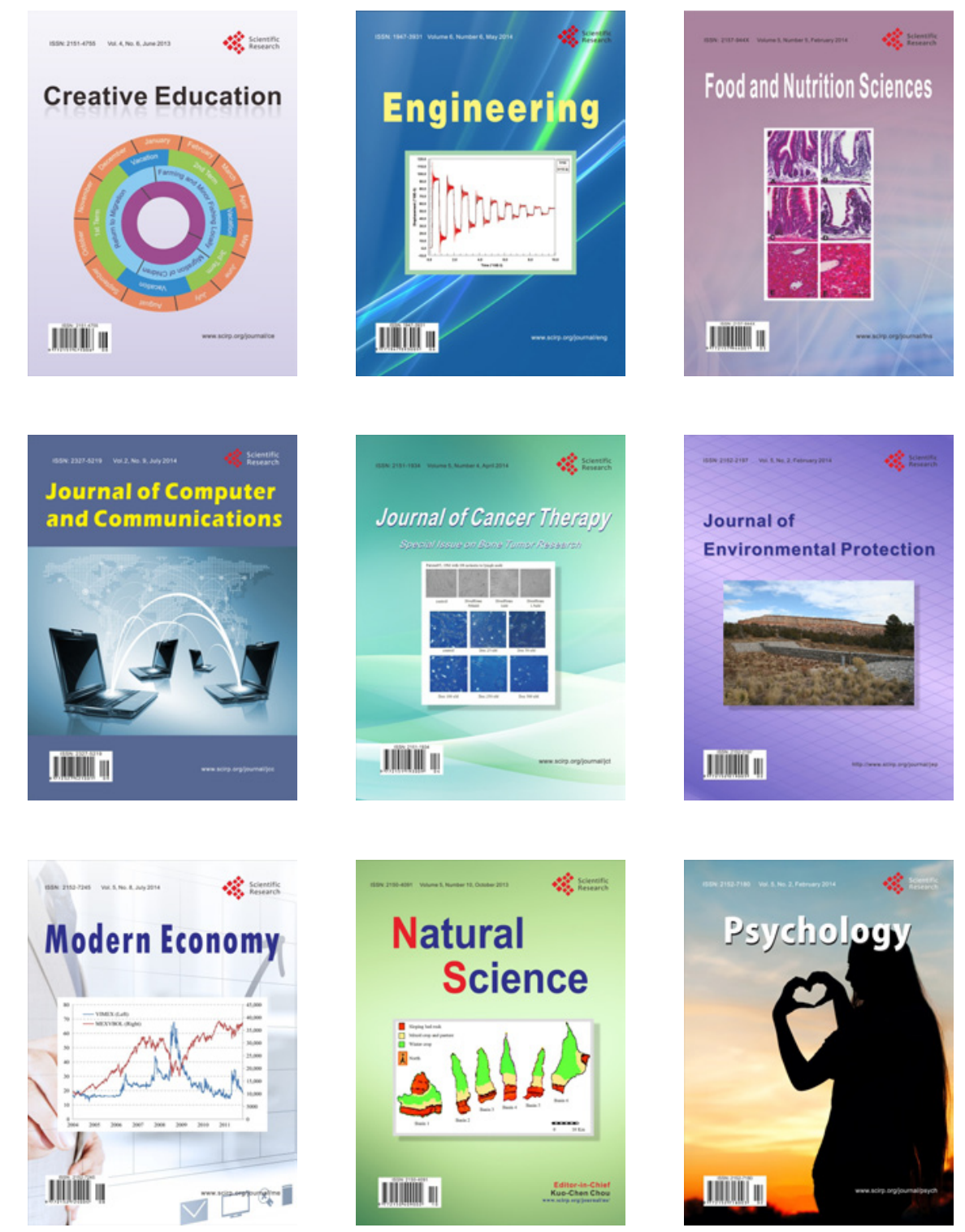